\title{
Can Mechanical Injury Really Trigger Relapsing Polychondritis? The First Report From A Large Case Series
}

\section{Lei Zhang ( $\nabla$ fcczhangl6@zzu.edu.cn )}

Zhengzhou University First Affiliated Hospital https://orcid.org/0000-0003-4105-0824

\section{Shuang Yun}

Zhengzhou University First Affiliated Hospital

\section{Tiange Wu}

Zhengzhou University First Affiliated Hospital

\section{Yujie He}

Zhengzhou University First Affiliated Hospital

\section{Jinyan Guo}

Zhengzhou University First Affiliated Hospital

\section{Lishuai Han}

Zhengzhou University First Affiliated Hospital

Jiameng Lu

Zhengzhou University First Affiliated Hospital

\section{Xiaojun Liu}

Zhengzhou University First Affiliated Hospital

\section{Rui Yang}

Zhengzhou University First Affiliated Hospital

\section{Shitao Zhang}

Zhengzhou University First Affiliated Hospital

\section{Tianfang Li}

Zhengzhou University First Affiliated Hospital

\section{Shengyun Liu}

Zhengzhou University First Affiliated Hospital

\section{Research}

Keywords: Relapsing polychondritis, mechanical injury, pathogenesis, triggers

Posted Date: September 18th, 2020

DOI: https://doi.org/10.21203/rs.3.rs-78066/v1 
License: (c) (i) This work is licensed under a Creative Commons Attribution 4.0 International License. Read Full License 


\section{Abstract}

Objectives The triggers of relapsing polychondritis (RPC) are not fully characterized. This study was performed to explore the association between mechanical injuries and RPC.

Methods The history of mechanical injuries of 127 RPC patients was reviewed and confirmed. The characteristics and survivals of patients with mechanical injuries were analyzed.

Results Fifty-four patients (42.5\%) had 63 mechanical injuries, among which 17 were cartilage-related. Thirty mechanical injuries in 28 patients occurred in the preceding one year before disease onset. Patients with mechanical injuries $(n=54)$ had a higher proportion of female gender $(59.3 \%$ vs $38.4 \%$, $P=0.002)$ and similar features compared to those without injuries $(n=73)$, regarding clinical manifestations and mortality rate. Among 54 patients with mechanical injuries, patients with cartilage related injury $(n=17)$ had a significantly higher rate of tracheobronchial chondritis $(64.7 \%$ vs $27 \%, P=$ 0.008), a significantly lower rate of auricular chondritis $(35.3 \%$ vs $67.6 \%, P=0.026)$ and a relatively higher mortality rate( $29.4 \%$ vs $8.1 \%, P=0.041)$ compared with those with non-cartilage related injury $(n=37)$.

Conclusion Our findings suggest that both cartilage-related and non-cartilage related injury may be triggers of RPC and patients with cartilage related injury seem to be more severe than those without.

\section{Introduction}

Relapsing polychondritis (RPC) is a systemic inflammatory disease primarily affecting the cartilaginous tissues, including the ears, nose, larynx, tracheobronchial tree and joints, as well as non-cartilaginous tissues[1]. The first case of relapsing polychondritis was described in 1923 by Jaksch-Wartenhorst, but little attention was given to the entity until the 1960s, when Pearson et al. introduced the name "relapsing polychondritis"[2].

The pathogenesis of RPC remains largely unknown[3,4]. However, it was postulated that it is an autoimmunity-mediated disorder and both cellular and humoral immunities are involved in the process. In addition, there is strong correlation between the RPC susceptibility and the presence of HLA- DR4[5].

However, the triggers of this rare disorder are not fully characterized. Several case reports suggest that cartilage injury may initiate RPC process[6-8], while solid evidence from large case series is not available. In the present study, we retrospectively reviewed the history of mechanical injury, aiming to establish an association between mechanical injury and the onset of RPC.

\section{Methods}

\section{Patients}

This study included 127 RPC patients who were hospitalized and followed-up by rheumatologists at our hospital between January, 2008 and March, 2020. RPC was diagnosed based on traditional criteria 
proposed by Michet et al. [9] and Damiani et al[10]. Partial and limited RPC was also defined as suggested by Mathew et al.[11] and our previous report[12]. Patients younger than 18 years and patients with positive anti-neutrophilic cytoplasmic antibody (ANCA) were excluded as suggested by Piette and colleagues [13]. The history of trauma or surgery was reviewed and confirmed. The sites and type of surgery or trauma and the intervals between these events and disease onset were recorded. Additionally, the demographic data, clinical manifestations, inflammatory index, survival data were all recorded during follow-up.

\section{Statistical Analysis}

Descriptive statistics were used to describe type of mechanical events and chronological occurrence, and all results were expressed as mean \pm standard deviation (SD), or percentage (\%) where appropriate. Comparisons of continuous variables were performed using Student's t-test. Categorical data were compared using Chi-squared or Fisher's exact test. Kaplan-Meier curves were generated to estimate the survival rates. Statistical significance was defined as two-sided $P$ value $<0.05$. Statistical analyses were performed using the SPSS version 17.0 software package (IBM).

\section{Results}

\section{Description of mechanical injuries}

Out of the 127 RPC patients, 54 patients (42.5\%) had 63 mechanical injuries, including 47 surgical procedures and 16 traumatic events, among which 9 patients experienced two mechanical or traumatic events ( 7 patients with two surgical procedures and 2 patients with one traumatic event and one surgical procedure each).

There were 17 cartilage-related injuries, including 14 ENT procedures, 2 teeth extraction and 1 trachea intubation, as well as 46 non-cartilage-related injuries, including 16 bone injuries (11 with long bone injuries, 3 with cranial bone trauma or procedure and 1 with lumbar procedures), 11 gastrointestinal procedures, 7 with obstetrical-gynecological procedures, and 12 with other injuries (3 cutaneous injuries, 4 breast procedures, 3 thyroidectomy, 1 ophthalmological procedure and 1 popliteal cyst operation) .

Trends of cartilage related and non-cartilage related injuries was showed in figure 1 in chronological order (Supplementary figure 1 for more details). The earliest mechanical injury occurred 40 years before disease onset, and there were only occasional mechanical injury until 5 years before disease onset. Mechanical injuries (both cartilage related and non-cartilage related) peaked in the preceding one year, especially 6 months, before disease onset. Thirty mechanical injuries in 28 patients occurred in the preceding one year before disease onset.

\section{Characteristics of patients with mechanical injuries}

RPC patients with mechanical injuries (group $A, n=54$ ) presented similar features to those without injuries (group $B, n=73$ ) regarding clinical manifestations and mortality rate, except a significantly higher 
proportion of female gender in group A ( $59.3 \%$ vs $38.4 \%, \mathrm{P}=0.002)$ (Figure $2 \mathrm{~A}$ and Supplementary Table 1). In addition, there was no difference of the survival curve between these two groups of patients (Figure 2C).

Among 54 patients with mechanical injuries, tracheobronchial chondritis was more prevalent in 17 patients with cartilage-related injury (group C) $(64.7 \%$ vs $27 \%, P=0.008)$, while auricular chondritis were more prevalent in 37 patients with non-cartilage-related injury (group D) $(67.6 \%$ vs $35.3 \%, P=0.026)$ (Figure 2B and Supplementary Table 2). A significantly higher mortality ratewas also found in group $\mathrm{C}$ compared with group D $(29.4 \%$ vs $8.1 \%, P=0.041)$ (Figure 2B and Supplementary Table 2$)$. Survival curve was significantly lower for group $C$ compared with group $D$ (Long rank test, $P=0.023$ ) (Figure 2D).

\section{Discussion}

This is the first case series that describe mechanical injuries as triggering factors among relapsing polychondritis patients. Two fifths of our patients ever had mechanical injuries while one fifth had mechanical injury in the preceding one year before disease onset. RPC patients with cartilage-injury seem to be more severe than those without, since they had higher incidence of airway involvement and relative lower survival rate.

Several RPC cases triggered by auricular piercing have been reported[6, 7]. However, most of our cartilageinjured patients experienced not only auricular injury, but also injury of nasal cartilage, laryngotracheal cartilage, voice cord, external auditory canal and mandible (tooth extraction), which expanded the triggering factors related to cartilage injury. Interestingly, some of our patients underwent surgical procedures or trauma that did not affect cartilaginous tissues, such as surgical procedures of intestinal tract, breast, thyroid, obstetric and ophthalmologic operations, which has never been reported. Our findings suggest that both cartilage-related and non-cartilage-related injury may be triggers of RPC. One reasonable explanation is that these injured structures share the same antigens in extra-cellular matrix, including collagens, cartilage oligomeric matrix protein (COMP) and matrilins (see online supplementary table 3 and supplementary text), which can be exposed after mechanical injury, causing activation of the immune system by multiple signaling pathways as hypothesized by Carlos A. C and colleagues [14].

Another point that should be stressed is that some mechanical injuries occurred many years before disease onset, which makes the link between mechanical injuries and PRC pathogenesis elusive. We postulated that these injuries may be the first striking initiating low-grade immune response until reaching the threshold, and the second hits, which are not clear yet, may lead to the onset of RPC. Similar scenarios have been noticed in different autoimmune inflammatory disease, such as rheumatoid arthritis, in which autoantibodies preceded the disease onset many years ago[15, 16]. As such, we postulate that the mechanical injuries may predispose these patients to the risk of developing RPC.

Three fifths of our patients did not have mechanical injuries, which indicates that there may be other triggering factors apart from mechanical injuries. For example, infection $[17,18]$ and some drugs $[19,20]$ was reported to be associated with RPC. 
Limitations of the present study derive from its retrospective nature inherent to all retrospective studies, which may resulted in incomplete information regarding the history of mechanical injury. However, we telephoned to patients that could be connected to confirm this, which may overcome this shortcoming in some extent.

\section{Conclusions}

In summary, we report that two fifths of our patients ever experience mechanical injuries before disease onset, which may confirm the triggering role of these mechanical events in pathogenesis of RPC. We believe this is the first report of relatively large case series focusing on this topic, and further prospective study is needed to confirm the causal relationship between mechanical injury and RPC and the pathogenesis need to be investigated deeply to identify novel effective targets for intervention.

\section{Abbreviations}

RPC: relapsing polychondritis; ANCA: anti-neutrophilic cytoplasmic antibody; COMP: cartilage oligomeric matrix protein

\section{Declarations}

\section{Ethics approval and consent to participate}

This retrospective cohort study was approved by the Ethic Committee of Zhengzhou University (SR-2018LW-050) and was conducted in accordance with the Declaration of Helsinki.

\section{Consent for publication}

Not applicable.

\section{Availability of data and materials}

The datasets analysed during the current study are available from the corresponding author on reasonable request.

\section{Competing interests}

The authors declare no conflict of interest.

\section{Funding}

No specific funding was received from any bodies in the public, commercial or not-for-profit sectors to carry out the work described in this article.

\section{Author's Contributions}


L.Z., S.L. and T.L. designed the study; LZ., S.Y.XT.W., Y.H., J.G., L.H., J.L., X.L., R.Y. and S.Z. collected the data; L.Z. and S.Y. analyzed data, performed statistical analysis and wrote the manuscript; T.L. revised the manuscript. All authors read and approved the final manuscript.

\section{Acknowledgements}

We thank our colleagues for their assistance in data collection and analysis.

\section{References}

1. Lahmer T, Treiber M, von Werder A, Foerger F, Knopf A, Heemann U, Thuermel K: Relapsing polychondritis: An autoimmune disease with many faces. Autoimmun Rev 2010, 9(8):540-546.

2. Pearson CM, Kline HM, Newcomer VD: Relapsing polychondritis. N Engl J Med 1960, 263:51-58.

3. Mathian A, Miyara M, Cohen-Aubart F, Haroche J, Hie M, Pha M, Grenier P, Amoura Z: Relapsing polychondritis: A 2016 update on clinical features, diagnostic tools, treatment and biological drug use. Best Pract Res Clin Rheumatol 2016, 30(2):316-333.

4. Rednic S, Damian L, Talarico R, Scire CA, Tobias A, Costedoat-Chalumeau N, Launay D, Mathian A, Mattews $L$, Ponte $C$ et al: Relapsing polychondritis: state of the art on clinical practice guidelines. RMD Open 2018, 4(Suppl 1):e000788.

5. Zeuner M, Straub RH, Rauh G, Albert ED, Scholmerich J, Lang B: Relapsing polychondritis: clinical and immunogenetic analysis of 62 patients. J Rheumatol 1997, 24(1):96-101.

6. Alissa $\mathrm{H}$, Kadanoff $\mathrm{R}$, Adams $\mathrm{E}$ : Does mechanical insult to cartilage trigger relapsing polychondritis? Scand J Rheumatol 2001, 30(5):311.

7. Serratrice J, Ene N, Granel B, Disdier P, deRoux-Serratrice C, Swiader L, Moulin G, Giovanni A, Weiller PJ: Severe relapsing polychondritis occurring after ear piercing. J Rheumatol 2003, 30(12):27162717.

8. Canas CA, Gomez AR, Echeverri AF, Quintana-Duque MA, Toro CE, Iglesias-Gamarra A: Patients with relapsing polychondritis and previous cartilage trauma present more autoimmunity phenomena. Rheumatol Int 2012, 32(2):541-543.

9. Michet CJ, Jr., McKenna CH, Luthra HS, O'Fallon WM: Relapsing polychondritis. Survival and predictive role of early disease manifestations. Ann Intern Med 1986, 104(1):74-78.

10. Damiani JM, Levine HL: Relapsing polychondritis-report of ten cases. Laryngoscope 1979, 89(6 Pt 1):929-946.

11. Mathew SD, Battafarano DF, Morris MJ: Relapsing polychondritis in the Department of Defense population and review of the literature. Semin Arthritis Rheum 2012, 42(1):70-83.

12. Zhang L, Wu TG, He YJ, Guo JY, Han LS, Lu JM, Liu SY, Li TF: Diagnosing relapsing polychondritis remains a common challenge: experience from a Chinese retrospective cohort. Clin Rheumatol 2020.

13. Piette JC, Dion J, Costedoat-Chalumeau N: News on Relapsing Polychondritis: The Patient's Experience. Arthritis Care Res (Hoboken) 2018, 70(8):1121-1123. 
14. Canas CA, Bonilla Abadia F: Local cartilage trauma as a pathogenic factor in autoimmunity (one hypothesis based on patients with relapsing polychondritis triggered by cartilage trauma). Autoimmune Dis 2012, 2012:453698.

15. Nielen MM, van Schaardenburg D, Reesink HW, van de Stadt RJ, van der Horst-Bruinsma IE, de Koning MH, Habibuw MR, Vandenbroucke JP, Dijkmans BA: Specific autoantibodies precede the symptoms of rheumatoid arthritis: a study of serial measurements in blood donors. Arthritis Rheum 2004, 50(2):380-386.

16. Sokolove J, Bromberg R, Deane KD, Lahey LJ, Derber LA, Chandra PE, Edison JD, Gilliland WR, Tibshirani RJ, Norris JM et al: Autoantibody epitope spreading in the pre-clinical phase predicts progression to rheumatoid arthritis. PLoS One 2012, 7(5):e35296.

17. Herrera I, Concha R, Molina EG, Schiff ER, Altman RD: Relapsing polychondritis, chronic hepatitis C virus infection, and mixed cryoglobulemia. Semin Arthritis Rheum 2004, 33(6):388-403.

18. Menge T, Rzepka R, Melchers I: Monoclonal autoantibodies from patients with autoimmune diseases: specificity, affinity and crossreactivity of MAbs binding to cytoskeletal and nucleolar epitopes, cartilage antigens and mycobacterial heat-shock protein 60 . Immunobiology 2002, 205(1):1-16.

19. Hernandez MV, Ruiz-Esquide V, Gomez-Caballero ME, Gomez-Puerta JA, Canete JD, Sanmarti R: Relapsing polychondritis: a new adverse event secondary to the use of tumour necrosis factor antagonists? Rheumatology (Oxford) 2011, 50(8):1523-1525.

20. Furer V, Wieczorek RL, Pillinger MH: Bilateral pinna chondritis preceded by glucosamine chondroitin supplement initiation. Scand J Rheumatol 2011, 40(3):241-243.

\section{Figures}




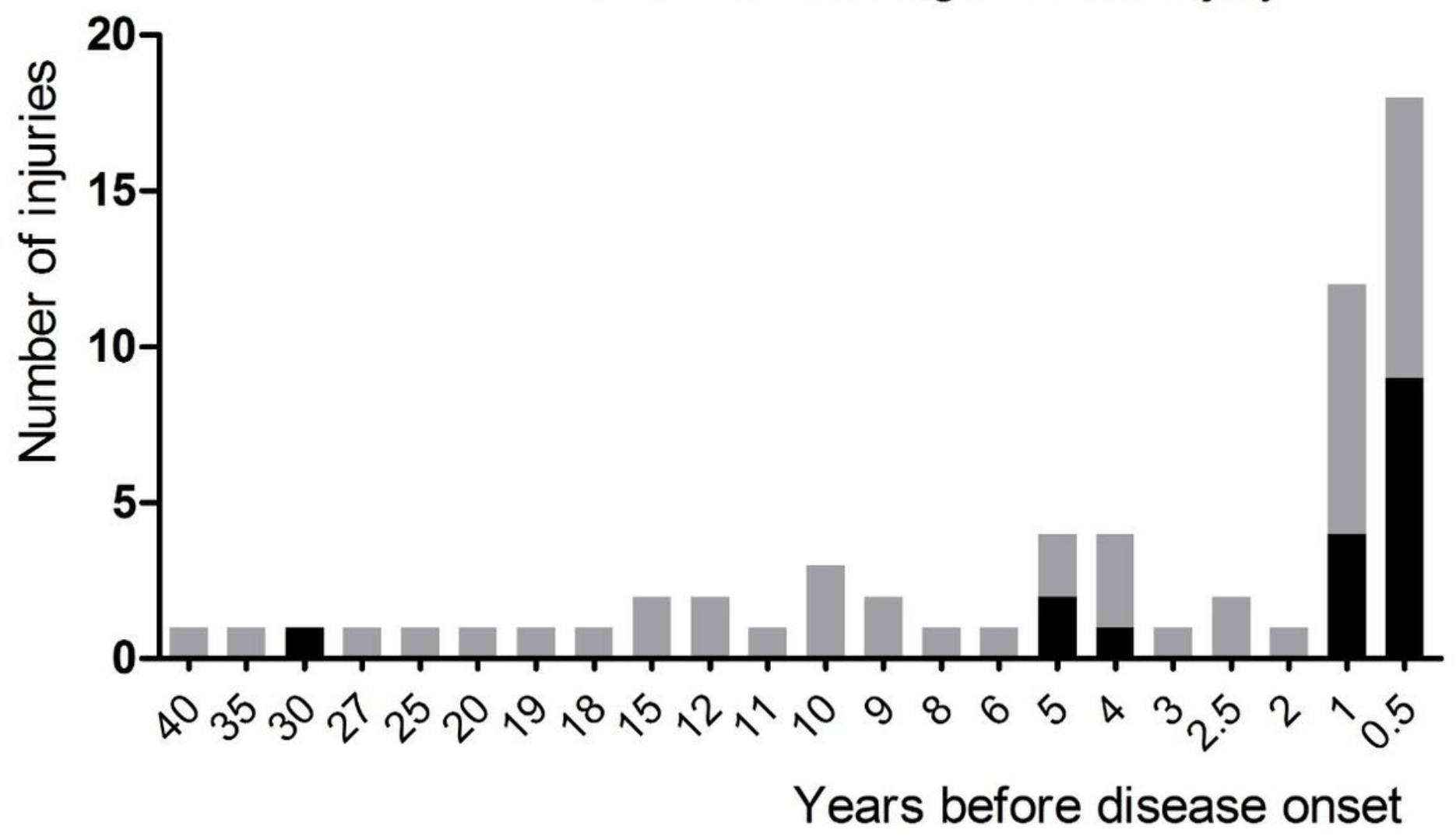

Figure 1

Chronological order of mechanical injuries that occurred before RPC onset. 

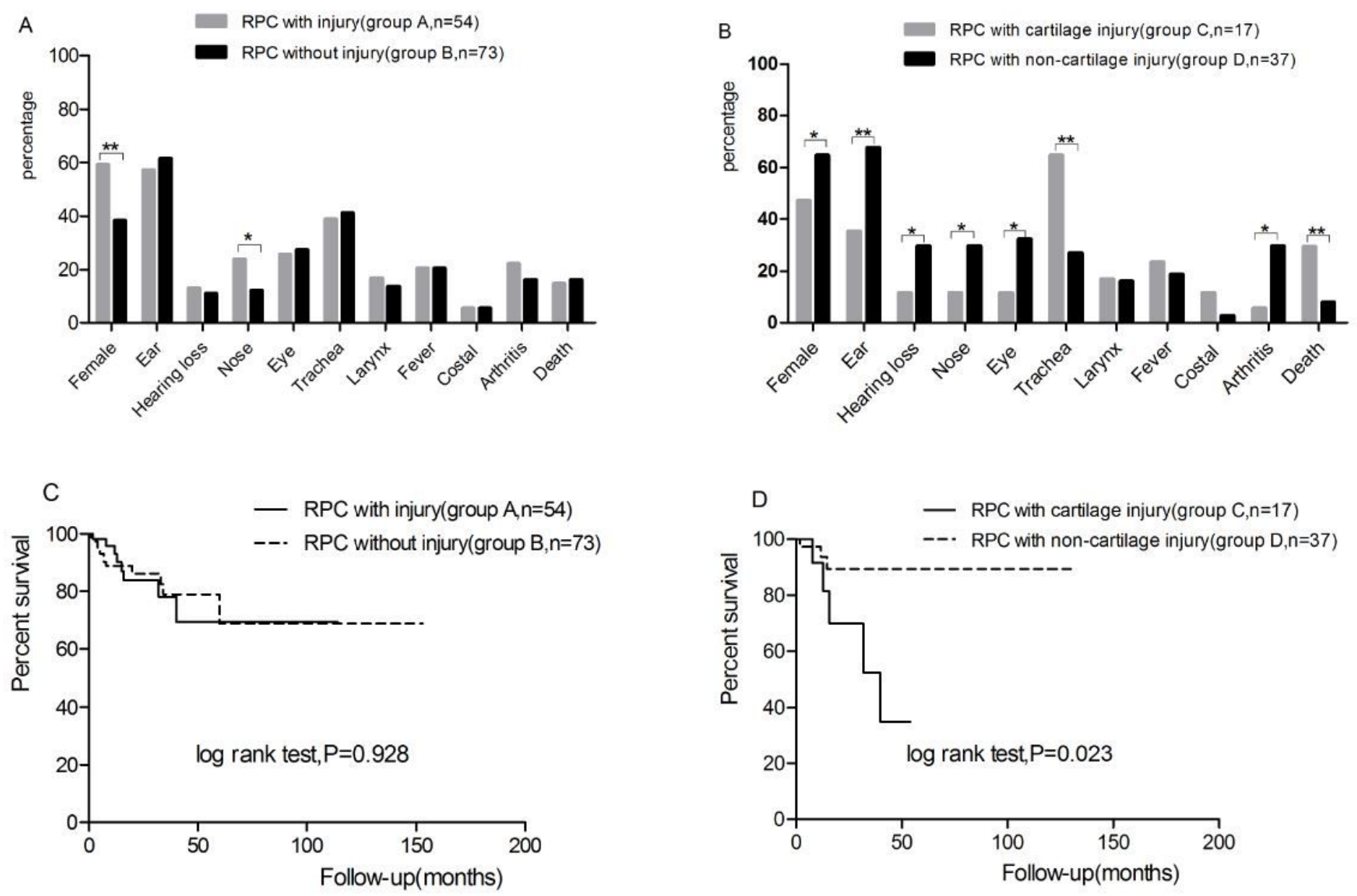

Figure 2

Comparison between different RPC patients. A. Characteristics compared between patients with injury(group $A, n=54$ ) and those without(group $B, n=73$ ). B. Characteristics compared between patients with cartilage injury (group $C, n=17$ ) and those with non-cartilage injury (group $D, n=37$ ).For more detailed data, please see supplementary tables. C. Comparison of Kaplan-Meier survival curves between patients with injury (group $A, n=54$ ) and those without(group B, n=73). D. Comparison of Kaplan-Meier survival curves between patients with cartilage injury (group $C, n=17$ ) and those with non-cartilage injury (group $D$, $n=37)$. *Numerical difference but without statistical significance, $P>0.05 * \star$ Difference with statistical significance, $\mathrm{P}<0.05$ Notes: Ear, auricular chondritis; Nose, nasal chondritis; Eye, eye inflammation; Trachea, tracheobronchial involvement; Larynx, Laryngeal involvement; Costal, costal chondritis.

\section{Supplementary Files}

This is a list of supplementary files associated with this preprint. Click to download.

- Supplementaryfiles.docx

- Supplementarytable3.docx 